\title{
Spatiotemporal variations in the stress field in the northeasternmost part of the NE Japan arc: constraints from microearthquakes
}

\author{
Sumire Maeda ${ }^{* *}$, Toru Matsuzawa ${ }^{2}$, Tomomi Okada² ${ }^{2}$, Hiroshi Katao ${ }^{3}$, Takeyoshi Yoshida ${ }^{2}$, \\ Masahiro Kosuga ${ }^{4}$ and Makoto Otsubo ${ }^{1}$ (])
}

\begin{abstract}
We determined focal mechanism solutions of microearthquakes and examined the stress field in the low-seismicity region from southern Hokkaido to eastern Aomori, NE Japan. The stress fields determined in this study comprise (1) a reverse faulting stress regime in southern Hokkaido with the axis of maximum compressional stress $\left(\sigma_{1}\right)$ being subhorizontal and trending WNW-ESE, and (2) a stress regime in eastern Aomori to Tsugaru Strait that shows temporal variations and differential stress of less than tens of $\mathrm{MPa}$. The spatiotemporal variation in stress from eastern Aomori to Tsugaru Strait might reflect the effects of the upper-plate bending and the $2011 M_{w} 9.0$ Tohoku-Oki earthquake. It also indicates that the compressional stress caused by the descending Pacific plate is relatively weak, which is similar to other areas in eastern parts of the NE Japan arc.
\end{abstract}

Keywords: Focal mechanism, Stress field, Low-seismicity area, Microseismicity, Forearc, Northeastern Japan, Pacific plate subduction, Kurile arc

\section{Introduction}

The stress field in inland areas of NE Japan is generally recognized as being associated with a WNW-ESE compressional reverse-faulting stress regime (e.g., Townend and Zoback 2006; Terakawa and Matsu'ura 2010; Yukutake et al. 2015) related to subduction of the Pacific plate. However, recent studies have revealed that there is a localized stress field in these areas which is different from that expected from the subduction of the Pacific Plate and that the stress field is spatially inhomogeneous (e.g., Terakawa and Matsu'ura 2010; Imanishi et al. 2012, 2013; Yoshida et al. 2012, 2015, 2019). Given that the stress distribution is commonly estimated using focal mechanism data, it is difficult to estimate the stress field

\footnotetext{
*Correspondence: maeda.sumire@aist.go.jp

${ }^{1}$ Geological Survey of Japan, AIST Tsukuba Central, National Institute of Advanced Industrial Science and Technology, 7, Higashi-1-1-1, Tsukuba, lbaraki 305-8567, Japan

Full list of author information is available at the end of the article
}

in low-seismicity areas. However, to properly understand earthquake generation mechanisms, it is necessary to investigate the stress field in low-seismicity areas as well as in areas with high seismicity.

In Japan, the High-Sensitivity Seismograph Network (Hi-net) has been deployed nationwide by the National Research Institute for Earth Science and Disaster Resilience (NIED) since the $1995 M_{\mathrm{j}} 7.2$ Hyogo-ken-Nanbu (Kobe) earthquake, which has been greatly improved the ability for detecting microearthquakes (Obara et al. 2005). Applying the inversion method developed by Michael $(1984,1987)$ to micro- and small-earthquake focal mechanism data, Yoshida et al. (2015) defined the stress regime in the forearc region of the NE Japan, where the stress field had not previously been defined in detail owing to the low seismicity in the region.

Here, we focus on the low-seismicity area from southern Hokkaido (region $\mathrm{N}$ ) to eastern Aomori (region S), Japan (Fig. 1), where the stress field was not previously estimated by Yoshida et al. $(2015,2019)$. This 


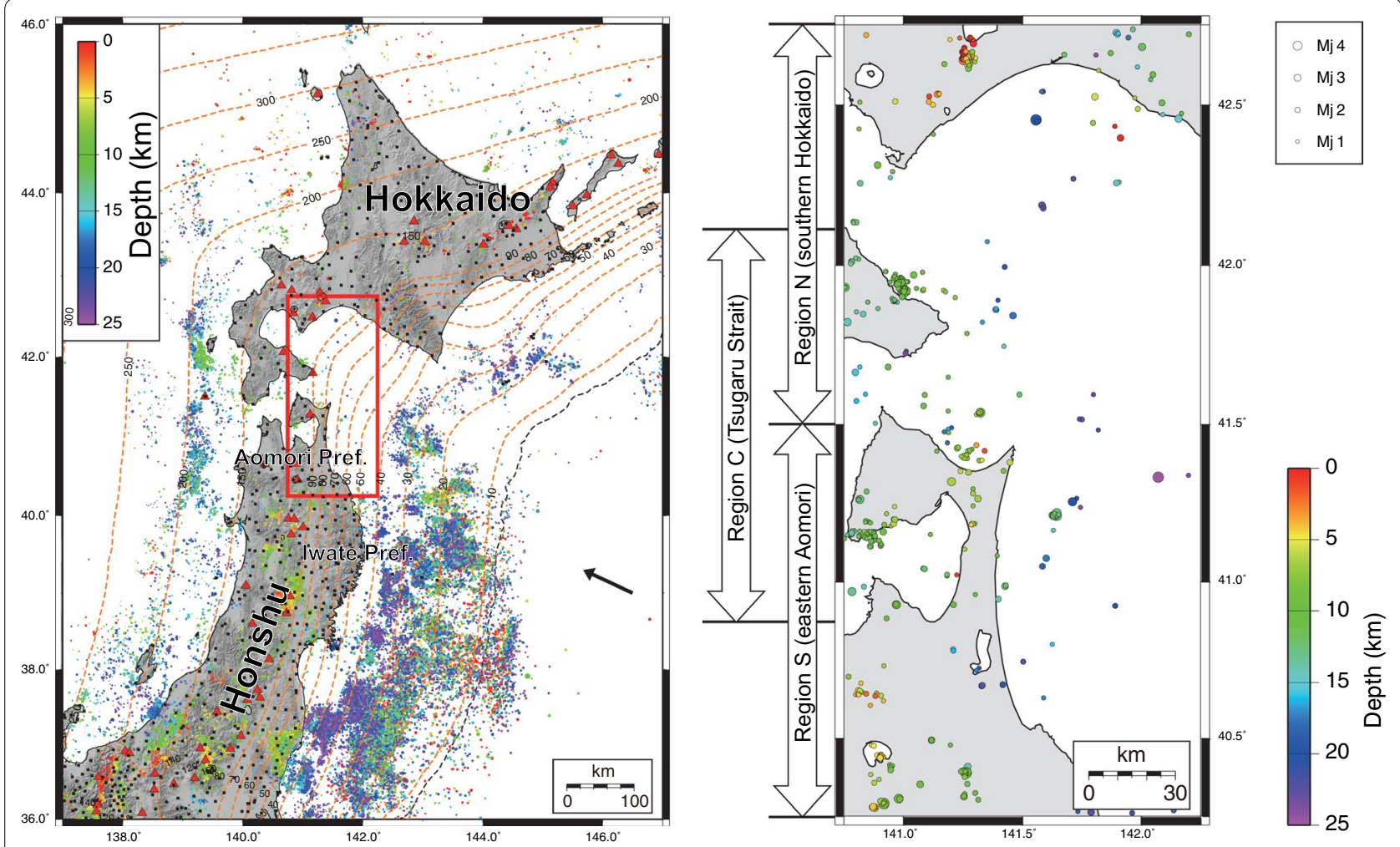

Fig. 1 Tectonic setting and hypocenter distribution in and around the study area. (Left) Hypocenter distribution in NE Japan. The red rectangle indicates the location of the study area shown in the right-hand panel. Thin broken black and orange lines show the position of the Japan trench and depth contours (in km) for the upper surface of the Pacific slab, respectively (Nakajima and Hasegawa, 2006; Kita et al. 2010). The arrow shows the direction of plate motion of the Pacific plate relative to the Okhotsk plate (Wei and Seno 1998). Red triangles denote active volcanoes. Circles denote hypocenters determined by JMA (3 June 2002 to 31 December 2017). (Right) Hypocenter distribution in the study area, with hypocenter depth shown by the color scale. The northern and southern parts of the study area are referred to as "region N" (southern Hokkaido) and "region $\mathrm{S}^{\prime \prime}$ (eastern Aomori), respectively. The region combining the southern half of region $\mathrm{N}$ and the northern half of region $\mathrm{S}$ is referred to as "region C" (Tsugaru Strait)

region corresponds to the northeasternmost part of the NE Japan arc (Fig. 1a), which is colliding with the Kurile arc. The stress field in Iwate Prefecture, which is located to the south of region $\mathrm{S}$, has been determined by Yoshida et al. $(2015,2019)$. Although the detailed stress distribution has not been determined because of the low seismicity in Hokkaido, including region $\mathrm{N}$, the orientation of maximum horizontal compressive stress $\left(\sigma_{\mathrm{Hmax}}\right)$ has been estimated to be roughly parallel to the relative motion of the Pacific plate (e.g., Ghimire et al. 2005; Terakawa and Matsu'ura 2010; Yukutake et al. 2015). Previous estimates of the stress field are also consistent with the regional stress field estimated from the strikes of ore veins (Watanabe 1986). However, because the seismicity in the study area is very low and no large events have occurred since the deployment of $\mathrm{Hi}$-net, the stress field in this area has not been determined in detail. Since the seismic waveform data have accumulated over time since the deployment of the
Hi-net, it is possible to estimate the stress field in this area now.

In this paper, we first determine the focal mechanisms of micro and small earthquakes from southern Hokkaido to eastern Aomori. We then examine the spatiotemporal variation in the stress field in the study area. Finally, we discuss the factors affecting the stress field in the northeasternmost part of the NE Japan arc.

\section{Data and methods}

\section{Hypocenter and focal mechanism data}

We used waveform data obtained by Hi-net for events with Japan Meteorological Agency (JMA) magnitudes greater than 2.0 for the period from June 2002 to December 2017, for depths shallower than $25 \mathrm{~km}$ (Fig. 1b). We determined hypocenters and focal mechanisms via these data and the following method. First, we picked P-wave first-motion polarities and onsets from the digital waveform data of each earthquake using the WIN system (Urabe and Tsukada 1992). Next, we determined 
hypocenters using the Hypomh program (Hirata and Matsu'ura 1987) with the one-dimensional velocity model of Hasegawa et al. (1978). We then used the software pick2mec (Katao and lio 2004) to determine focal mechanisms using the phase data and the hypocenters. The pick $2 \mathrm{mec}$ software uses a procedure proposed by Maeda (1992) to determine the focal mechanisms. This software assigns each focal mechanism a score based on the ratio of consistent polarities to all polarities. Finally, we retained only reliable solutions using the same quantitative criterion as employed by Maeda et al. (2018). Moreover, we evaluated the uncertainty of focal mechanisms by measuring the extent of these multiple fault plane solutions estimated using pick2mec with the Kagan angle (Kagan 1991). Focal mechanisms with an uncertainty in the Kagan angle of $>35^{\circ}$ were discarded.

\section{Stress inversion}

We used the focal mechanisms obtained using the method given above to determine the stress field. We used an ordinary stress inversion procedure similar to those proposed by Michael $(1984,1987)$. This technique assumes the stress to be uniform within an analysis area and minimizes the difference between observed and calculated slip directions. The method can be used to estimate the orientations of stress axes and the stress ratio $R=\left(\sigma_{1}-\sigma_{2}\right) /\left(\sigma_{1}-\sigma_{3}\right)$, where $\sigma_{1}, \sigma_{2}$, and $\sigma_{3}$ are the maximum, intermediate, and minimum compressional principal stresses, respectively. Using the above data and method, we estimated the stress field in regions $\mathrm{N}, \mathrm{C}$, and $\mathrm{S}$ shown in Fig. 1b. In order to smoothly visualize the spatial variation of the stress field in this area with lowseismicity, the region of $\mathrm{C}$ is overlapped on the regions of $\mathrm{N}$ and $\mathrm{S}$. Then, we examined whether the stress field varied spatiotemporally. To investigate spatial variations, we compared the stress field in the three regions. To investigate temporal variations, we divided the studied time interval into two periods, before and after the Mw 9.0 Tohoku-Oki earthquake (herein, Tohoku earthquake) that occurred on 11 March 2011, and compared the stress fields determined for these periods.

\section{Results}

We successfully determined reliable focal mechanisms for 114 events, which is $21 \%$ of all candidate events in this study. The determined focal mechanisms for the periods before and after the Tohoku earthquake are shown in Fig. 2a, b, respectively. A comparison of Figs. $1 \mathrm{~b}$ and 2 shows that the focal mechanisms of earthquakes distributed off the coast could not be estimated because there are no offshore stations. The stress inversion results for regions $\mathrm{N}, \mathrm{C}$, and $\mathrm{S}$ for the periods before and after the Tohoku earthquake are shown in Fig. 3a, b, respectively.
For the period before the earthquake, the result of the stress tensor inversion in region $\mathrm{N}$ indicates that this region is characterized by a reverse faulting stress regime with $\sigma_{1}$ axis being sub-horizontal, trending between $\mathrm{E}-\mathrm{W}$ and WNW-ESE. The stress ratio is $<0.5$, which indicates that the magnitude of $\sigma_{2}$ is closer to $\sigma_{1}$ than to $\sigma_{3}$ (region $\mathrm{N}$ in Fig. 3a). In contrast, the results of the stress tensor inversion in regions $\mathrm{C}$ and $\mathrm{S}$ indicate that these regions are characterized by a reverse faulting stress regime with $\sigma_{1}$ axis being sub-horizontal and trending between $\mathrm{N}-\mathrm{S}$ and NNE-SSW. The stress ratios show a wide distribution (regions $\mathrm{C}$ and $\mathrm{S}$ in Fig. 3a).

For the period after the Tohoku earthquake, region $\mathrm{N}$ is characterized by a reverse faulting stress regime with $\sigma_{1}$ axis being sub-horizontal and trending WNW-ESE; the stress ratio is generally $<0.5$ (region $\mathrm{N}$ in Fig. $3 \mathrm{~b}$ ). Thus, the stress regime in region $\mathrm{N}$ is similar before and after the Tohoku earthquake. In contrast, the results of the stress tensor inversion in regions $\mathrm{C}$ and $\mathrm{S}$ indicate that these regions are characterized by a reverse faulting stress regime with $\sigma_{1}$ axis being sub-horizontal and trending ENE-WSW; the stress ratio is $\sim 0.5$ (regions $\mathrm{C}$ and $S$ in Fig. 3b).

Our results indicate only minor temporal variations in the stress field in region $\mathrm{N}$ for the periods before and after the Tohoku earthquake. We consider this stress field to be associated with subduction of the Pacific plate, as discussed below. In contrast, the stress field in regions $\mathrm{C}$ and $\mathrm{S}$ clearly shows temporal variations though the scatter of the axis is larger before the Tohoku earthquake. The stress field differs from the generally recognized WNW-ESE compressional reverse faulting stress regime in NE Japan, regardless of the period before and after the Tohoku earthquake.

\section{Discussion}

\section{Temporally variable stress field from eastern Aomori to Tsugaru Strait}

Our study results indicate that the stress field in regions $\mathrm{C}$ and $\mathrm{S}$ differs from that expected from subduction of the Pacific plate. In this section, we discuss the temporal variation in the stress field in these regions, in detail.

The stress field in regions $\mathrm{C}$ and $\mathrm{S}$ for the period before the Tohoku earthquake shows a reverse faulting stress regime with the maximum compressional principal stress $\left(\sigma_{1}\right)$ axis being sub-horizontal and trending $\mathrm{N}-\mathrm{S}$. Recent studies have identified a region with sub-horizontal $\sigma_{1}$ axis trending $\mathrm{N}-\mathrm{S}$ in the forearc region in NE Japan, and ascribed this orientation to the effect of bending of the upper-plate due to interplate coupling and/or the effect of subducting plate interface curvature (Imanishi et al. 2012, 2013; Yoshida et al. 2015, 2019). Yoshida et al. (2015) suggested that in parts of the forearc region, E-W 


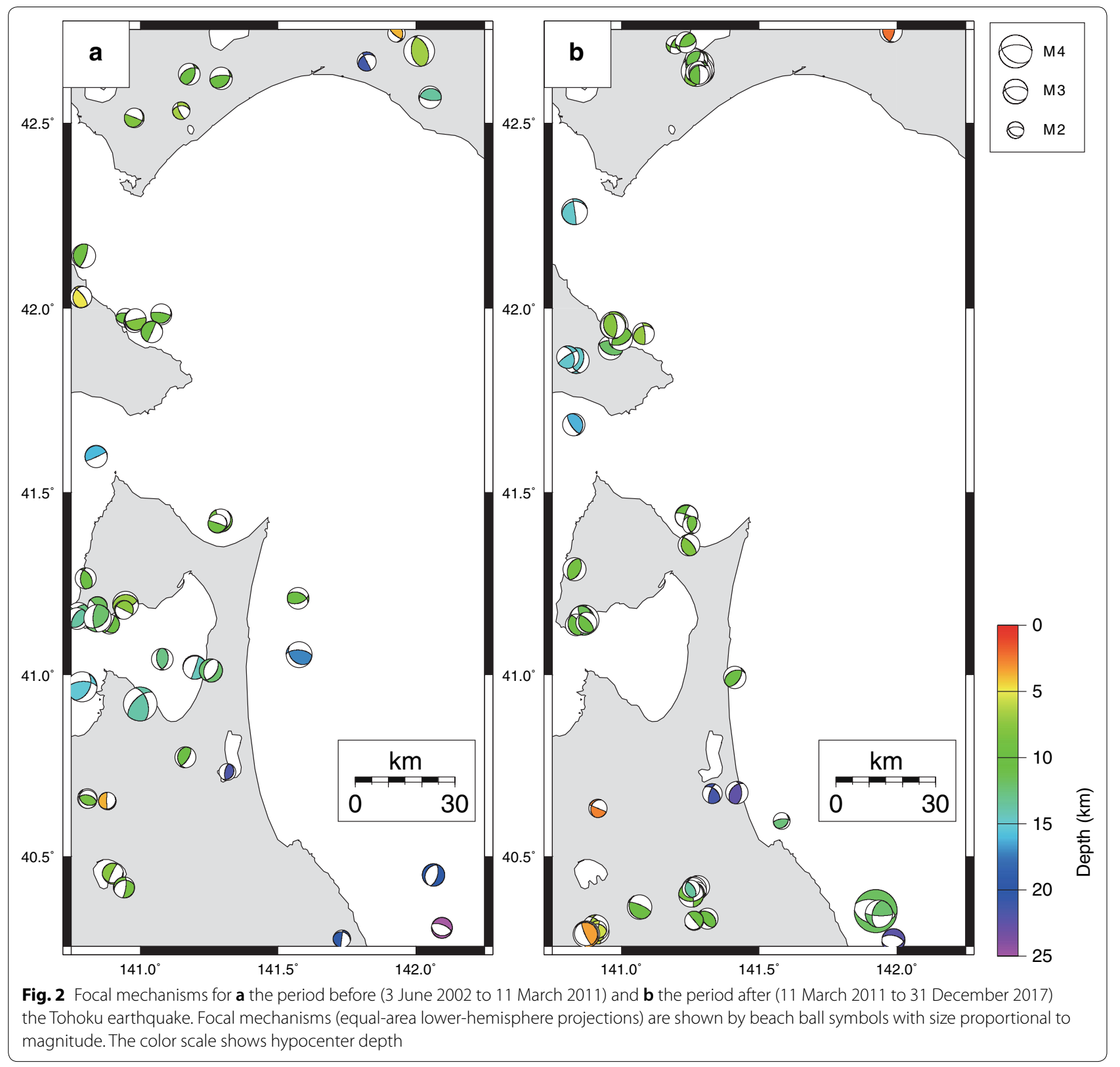

compressional stress is low compared with $\mathrm{N}-\mathrm{S}$ compressional stress because of upper-plate bending. The plate bending deformation produces $\mathrm{E}-\mathrm{W}$ extensional stress, and thus N-S compressional stress is relatively larger than the E-W compressional stress. N-S trending $\sigma_{1}$ axis in regions $\mathrm{C}$ and $\mathrm{S}$ can be similarly explained by the effect of upper-plate bending, because the regions are located at the northern margin of the forearc region in Honshu.

However, we also found that the stress field in regions $\mathrm{C}$ and $\mathrm{S}$ for the period after the Tohoku earthquake constitutes a reverse faulting stress regime with $\sigma_{1}$ axis being sub-horizontal and trending ENE-WSW, suggesting that $\sigma_{1}$ axis was rotated by $\sim 90^{\circ}$ as a result of the Tohoku earthquake. Since there is no significant difference in hypocenter distribution for the periods before and after the Tohoku earthquake in regions $\mathrm{C}$ and $\mathrm{S}$ (Fig. 2), this stress rotation cannot be explained as an artifact caused by spatial variation in the stress field or by a change in hypocenter distribution. Rather, the rotation in $\sigma_{1}$ axis is explained by the effect of the Tohoku earthquake, as follows. Yoshida et al. $(2012,2019)$ reported that the stress field in inland areas of eastern Honshu, Japan, changed as a result of the Tohoku earthquake. The stress field in regions $\mathrm{C}$ and $\mathrm{S}$ is consistent with that in inland areas that 


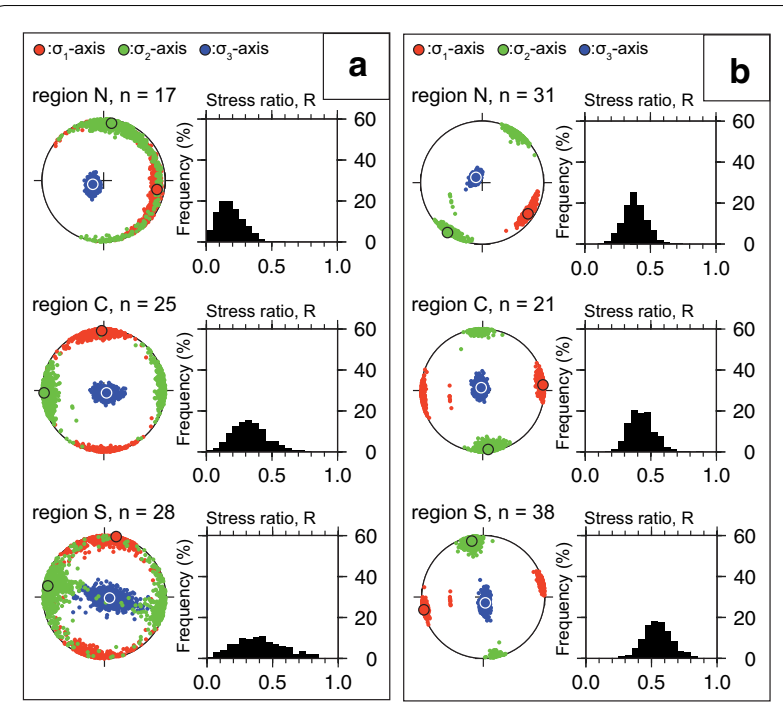

Fig. 3 Results of stress tensor inversion in regions $N, C$, and $S$ for $\mathbf{a}$ the period before (11 March 2011 to 3 June 2002) and $\mathbf{b}$ the period after (11 March 2011 to 31 December 2017) the Tohoku earthquake. The locations of these regions are shown in Fig. 1b. The left panel shows stress tensor inversion results. Red, green, and blue dots correspond to the $95 \%$ confidence regions of the $\sigma_{1}, \sigma_{2}$, and $\sigma_{3}$ axes, respectively, and red, green, and blue circles correspond to the best-fit solutions of the same axes, respectively. The right panel shows the frequency distributions of stress ratio $R$, where $R=\left(\sigma_{1}-\sigma_{2}\right) /$ $\left(\sigma_{1}-\sigma_{3}\right)$, for the respective regions

were affected by coseismic slip of the Tohoku earthquake (Yoshida et al. 2012, 2019). Such a stress change caused by the 2011 Tohoku earthquake could have triggered some earthquakes with unfavorable fault orientation with the typical WNW-ESE compressional stress field in NE Japan. In addition, the strain distribution obtained from GEONET [GNSS Earth Observation Network System, operated by the GSI (Geospatial Information Authority of Japan)] shows that ENE-WSW contraction and NNW-SSE extension were predominant in the period after the Tohoku earthquake in northernmost Honshu, including regions $\mathrm{C}$ and $\mathrm{S}$ (e.g., Figure 10 in Geospatial Information Authority of Japan 2018a). To release such strains, the ENE-WSW compressional reverse fault earthquakes may have been caused. All of the above suggests that the stress field in regions $C$ and $S$ for the period after the Tohoku earthquake was influenced by coseismic static stress change and postseismic crustal deformation related to the Tohoku earthquake.

Yoshida et al. (2012) reported that the Tohoku earthquake resulted in a coseismic change in differential stress of $<1 \mathrm{MPa}$ in the present study area. The strain change due to postseismic deformation (for the period up to 2017) is estimated to have been the order of $10^{-5}$ based on GNSS observations (Geospatial Information
Authority of Japan 2018b), which corresponds to the order of $1 \mathrm{MPa}$ change in the horizontal differential stress $\left(\sigma_{\mathrm{H} \max }-\sigma_{\mathrm{H} \min }\right)$ assuming a rigidity of 30-40 GPa. We just show an order-estimation of the strain change here because the strain change estimated from GNSS station data varies with a subjective weighting parameter (e.g., "distance-decaying constant" proposed by Shen et al. 1996); but we can safely conclude that the change in the horizontal differential stress $\left(\sigma_{\mathrm{Hmax}}-\sigma_{\mathrm{Hmin}}\right)$ due to the coseismic and postseismic deformation caused by the Tohoku earthquake should have been $<10 \mathrm{MPa}$. Thus, the value of $\left(\sigma_{1}-\sigma_{2}\right)$ before the occurrence of the Tohoku earthquake should have been also $<10 \mathrm{MPa}$ because horizontal $\sigma_{1}$ and $\sigma_{2}$ axes in the region $\mathrm{S}$ exchanged their directions after the earthquake as shown in Fig. 3. As the stress ratio is estimated to have been $\sim 0.3$ for the period before the Tohoku earthquake, the differential stress $\left(\sigma_{1}-\sigma_{3}\right)$ is thought to have been less than tens of MPa. The obtained differential stress is consistent with the estimate of Yoshida et al. $(2015,2019)$.

In regions $\mathrm{C}$ and $\mathrm{S}$, earthquakes are generated by movement on normal and strike-slip faults as well as reverse faults. Miyauchi (1985) identified geological folding structures in these regions that strike E-W as well as N-S. Bouguer anomaly patterns reveal small-scale structures with variable strike superimposed on largescale N-S-striking structures (Fig. 4; Yamamoto 2005). Based on the information shown above, it is considered that fault planes with various orientations exist in these regions. The occurrence of various fault types of earthquakes under such low differential stress in these regions may be due to the presence of such weak fault planes.

\section{Effect on the stress field of southwestward movement of the Kuril Forearc sliver in southern Hokkaido}

Our results show that the stress regime (reverse faulting with $\sigma_{1}$ axis oriented sub-horizontal and trending WNW-ESE) in region $\mathrm{N}$ was essentially unchanged between the periods before and after the Tohoku earthquake (Fig. 3). The results suggest that the effect of the subduction of the Pacific Plate is more dominant than the effect of the southwestward movement of the Kuril Forearc sliver (e.g., Kimura 1981, 1996; Seno 1985; Moriya 1986; Arita et al. 2001) on the stress field in this region even after the Tohoku earthquake.

On 6 September 2018, the Mw 6.6 Hokkaido Eastern Iburi earthquake (herein, the Iburi earthquake) occurred in the northeastern part of region N. Ohtani and Imanishi (2019) estimated the stress field around the northeastern edge of region $\mathrm{N}$ using the focal mechanism solutions of the aftershocks that occurred in the region indicated by a rectangle in Fig. 4. They found that this area is characterized by a reverse 


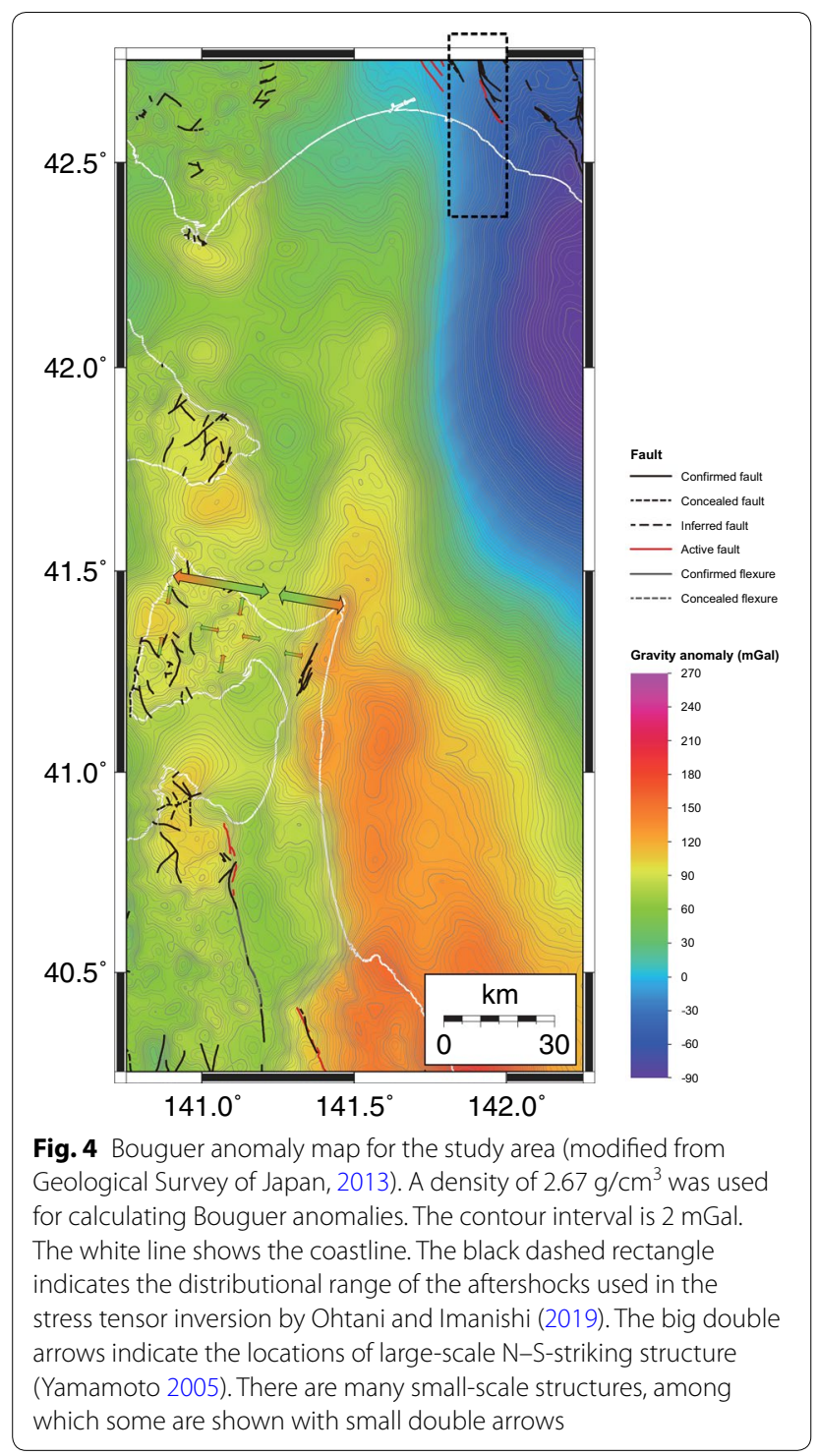

faulting stress regime with $\sigma_{1}$ axis oriented sub-horizontal and trending ENE-WSW, and suggested that this stress regime has resulted from southwestward migration of the Kuril Forearc sliver and its collision with NE Japan.

The focal mechanism solutions used in the present analysis for region $\mathrm{N}$ are located mostly in the western part of the region. Therefore, it is likely that the stress field changes between the western and eastern parts of region N. The Bouguer anomaly shown in Fig. 4 also shows the difference in the structure between the western and eastern parts there. However, the details of the spatial variation in the stress are unclear, owing to insufficient data. To overcome this limitation, it will be necessary to use data from ocean-bottom stations (e.g., NIED 2019a) in future work.

\section{Conclusions}

We determined the focal mechanisms of earthquakes in the low-seismicity region extending from southern Hokkaido to eastern Aomori (northeasternmost NE Japan arc) and investigated spatiotemporal variations in the stress field. Our results indicate that the stress regime in southern Hokkaido remained essentially unchanged after the Tohoku earthquake, whereas the regime changed after the earthquake in the region from eastern Aomori to Tsugaru Strait. The differential stress is estimated to be less than tens of MPa before the Tohoku earthquake in the latter regions.

\section{Abbreviations}

GNSS: Global Navigation Satellite System; Hi-net: High-Sensitivity Seismograph Network; JMA: Japan Meteorological Agency; $M_{\mathrm{j}}$ : JMA magnitude; $M_{\mathrm{w}}$ : Moment magnitude; NIED: National Research Institute for Earth Science and Disaster Resilience.

\section{Acknowledgements}

We thank T. Shiina at Geological Survey of Japan, for fruitful discussions. The authors thank the Lead Guest Editor Y. Tanioka and the reviewers T. Yamada and an anonymous reviewer for their helpful comments, which have greatly improved the manuscript. We used the JMA unified earthquake catalog and the NIED Hi-net catalog. We used "Slick Package" (http://earthquake.usgs.gov/ research/software/) software coded by Andrew Michael for stress tensor inversion. In the drawing of Fig. 1a, we used the "GSI Maps" web service provided by GSI (https://maps.gsi.go.jp/) as well as the scripts and grid data provided by F. Hirose at the Meteorological Research Institute (https://www.mri-jma. go.jp/Dep/sei/fhirose/plate/en.PAC.html). All of the figures in the paper were created using the Generic Mapping Tools (GMT) (Wessel and Smith 1998).

\section{Authors' contributions}

Data analysis and manuscript preparation were carried out mainly by SM. TM and TO supervised the study at all stages. HK led the waveform data analysis. TY, MK, and MO participated in the design of the study and discussion. All authors read and approved the final manuscript.

\section{Funding}

The main part of this research project was conducted as regulatory-supporting research funded by the Secretariat of Nuclear Regulation Authority (Secretariat of NRA), Japan.

\section{Availability of data and materials}

The seismic datasets used in this study are from NIED's Hi-net (NIED 2019b, https://doi.org/10.17598/nied.0003).

\section{Ethics approval and consent to participate}

Not applicable.

\section{Consent for publication}

Not applicable.

\section{Competing interests}

The authors declare that they have no competing interests.

\section{Author details}

${ }^{1}$ Geological Survey of Japan, AIST Tsukuba Central, National Institute of Advanced Industrial Science and Technology, 7, Higashi-1-1-1, Tsukuba, Ibaraki 305-8567, Japan. ${ }^{2}$ Graduate School of Science, Tohoku University, 6-6 Aza-Aoba, Aramaki, Aoba-ku, Sendai 980-8578, Japan. ${ }^{3}$ Research Center 
for Earthquake Prediction, Disaster Prevention Research Institute, Kyoto University, Gokasho, Uji, Kyoto 611-0011, Japan. ${ }^{4}$ Graduate School of Science and Technology, Hirosaki University, 3 Bunkyo-cho, Hirosaki, Aomori 036-8561, Japan.

Received: 2 June 2020 Accepted: 31 July 2020

Published online: 10 August 2020

\section{References}

Arita K, Ganzawa Y, Itaya T (2001) Tectonics and uplift process of the Hidaka Mountains, Hokkaido, Japan inferred from thermochronology. Bull Earthq Res Inst Univ Tokyo 76:93-104 (in Japanese with English abstract)

Geological Survey of Japan (2013) Gravity database of Japan, DVD edn. Geological Survey of Japan, AIST

Geospatial Information Authority of Japan (2018a) Crustal deformations of entire Japan, Rep Coord Comm Earthq Pred 99:8-17. https://cais.gsi. go.jp/YOCHIREN/report/kaihou99/01_03.pdf (in Japanese with English captions)

Geospatial Information Authority of Japan (2018b) Special feature: Seven years after the 2011 off the Pacific coast of Tohoku Earthquake https://www.gsi. go.jp/common/000198045.pdf (in Japanese)

Ghimire S, Katsumata K, Kasahara M (2005) Temporal changes in state of stress in the Tokachi Oki region after the 2003 Tokachi Oki earthquake. Earth Planets Space 57:83-91. https://doi.org/10.1186/BF03352552

Hasegawa A, Umino N, Takagi A (1978) Double-planed structure of the deep seismic zone in the northeastern Japan arc. Tectonophysics 47(1):43-58. https://doi.org/10.1016/0040-1951(78)90150-6

Hirata N, Matsu'ura M (1987) Maximum-likelihood estimation of hypocenter with original time eliminated using nonlinear inversion technique. Phys Earth Planet Inter 47:50-61. https://doi.org/10.1016/0031-9201(87)90066 $-5$

Imanishi K, Ando R, Kuwahara Y (2012) Unusual shallow normal-faulting earthquake sequence in compressional northeast Japan activated after the 2011 off the Pacific coast of Tohoku earthquake. Geophys Res Lett 39(9):L09306. https://doi.org/10.1029/2012GL051491

Imanishi K, Takeda N, Kuwahara Y (2013) On an activated normal-faulting earthquake sequence below the southern extremity of Lake Kasumigaura, central Japan, after the 2011 Off the Pacific Coast of Tohoku Earthquake. Zisin 66(3):47-66. https://doi.org/10.4294/zisin.66.47 (in Japanese with English abstract)

Kagan YY (1991) 3-D rotation of double-couple earthquake sources. Geophys J Int 106:709-716. https://doi.org/10.1111/j.1365-246X.1991.tb06343.x

Katao H, lio Y (2004) Focal mechanisms of microearthquakes in the Tamba Plateau. Ann Disast Prev Res Inst Kyoto Univ 47B:674-678 (in Japanese)

Kimura G (1981) Tectonic evolution and stress field in the southwestern margin of the Kurile Arc. J Geol Soc Japan 87:757-768. https://doi. org/10.5575/geosoc.87.757 (in Japanese with English abstract)

Kimura G (1996) Collision orogeny at arc-arc junctions in the Japanese Islands. Island Arc 5:262-275. https://doi.org/10.1111/j.1440-1738.1996.tb00031.x

Kita S, Okada T, Hasegawa A, Nakajima J, Matsuzawa T (2010) Anomalous deepening of a seismic belt in the upper-plane of the double seismic zone in the Pacific slab beneath the Hokkaido corner: possible evidence for thermal shielding caused by subducted forearc crust materials. Earth Planet Sci Lett 290:415-426. https://doi.org/10.1016/j.epsl.2009.12.038

Maeda N (1992) A method of determining focal mechanisms and quantifying the uncertainty of the determined focal mechanisms for microearthquakes. Bull Seismol Soc Am 82:2410-2429

Maeda S, Matsuzawa T, Toda S, Yoshida K, Katao H (2018) Complex microseismic activity and depth-dependent stress field changes in Wakayama, southwestern Japan. Earth Planets Space 70(1):21. https://doi. org/10.1186/s40623-018-0788-6

Michael AJ (1984) Determination of stress from slip data; faults and folds. J Geophys Res 89:11517-11526. https://doi.org/10.1029/JB089iB13p11517

Michael AJ (1987) Use of focal mechanisms to determine stress: a control study. J Geophys Res 92:357-368. https://doi.org/10.1029/JB092iB01p 00357

Miyauchi T (1985) Quaternary crustal movements estimated from deformed terraces and geologic structures of the Kamikita coastal plain, northeast
Japan. Geogr Rev Jpn 58:492-515. https://doi.org/10.4157/grj19 84a.58.8_492 (in Japanese with English abstract)

Moriya T (1986) Collision of forearcs and the overlapped deep seismic zone in the transitional zone between the northern Honshu and Kurile arcs. J Phys Earth 34:S175-S192. https://doi.org/10.4294/jpe1952.34

Nakajima J, Hasegawa A (2006) Anomalous low-velocity zone and linear alignment of seismicity along it in the subducted Pacific slab beneath Kanto, Japan: reactivation of subducted fracture zone? Geophys Res Lett 33:L16309. https://doi.org/10.1029/2006GL026773

National Research Institute for Earth Science and Disaster Resilience (2019a) NIED S-net. https://doi.org/10.17598/nied.0007

National Research Institute for Earth Science and Disaster Resilience (2019b) NIED Hi-net. https://doi.org/10.17598/nied.0003

Obara K, Kasahara K, Hori S, Okada Y (2005) A densely distributed high-sensitivity seismograph network in Japan: Hi-net by National Research Institute for Earth Science and Disaster Prevention. Rev Sci Instrum 76:021301. https://doi.org/10.1063/1.1854197

Ohtani M, Imanishi K (2019) Seismic potential around the 2018 Hokkaido Eastern Iburi earthquake assessed considering the viscoelastic relaxation. Earth Planets Space 71:57. https://doi.org/10.1186/s40623-019-1036-4

Seno T (1985) Northern Honshu microplate hypothesis and tectonics in the surrounding region: When did the plate boundary jump from central Hokkaido to the eastern margin of the Japan Sea? J Geodetic Soc Japan 31:106-123. https://doi.org/10.11366/sokuchi1954.31.106

Shen Z, Jackson DD, Ge BX (1996) Crustal deformation across and beyond the Los Angeles basin from geodetic measurements. J Geophys Res 101:957-980. https://doi.org/10.1029/96jb02544

Terakawa T, Matsu'ura M (2010) The 3-D tectonic stress fields in and around Japan inverted from centroid moment tensor data of seismic events. Tectonics 29:TC6008. https://doi.org/10.1029/2009tc002626

Townend J, Zoback MD (2006) Stress, strain, and mountain building in central Japan. J Geophys Res 111:22295-22311. https://doi.org/10.1029/2005J B003759

Urabe T, Tsukada S (1992) WIN: a workstation program for processing waveform data from microearthquake networks. Prog Abstr Seismol Soc Jpn 2:41 (in Japanese)

Watanabe $Y$ (1986) Neogene regional stress field inferred from the pattern of ore veins in Hokkaido, Japan. Mining Geol 36:209-218. https://doi. org/10.11456/shigenchishitsu1951.36.209 (in Japanese with English abstract)

Wei D, Seno T (1998) Determination of the Amurian plate motion. In: Flower MFM, Chung S-L, Lo C-H, Lee T-Y (eds) Mantle dynamics and plate interactions in East Asia, Geodynamics Series, 27. AGU, Washington D. C.

Wessel P, Smith W (1998) New, improved version of generic mapping tools released. EOS Trans AGU 79(47):579. https://doi.org/10.1029/98EO00426

Yamamoto A (2005) Gravity Anomaly and Shallow Crustal Structure of the Shimokita Peninsula, Northeastern Japan. Geophys Bull Hokkaido Univ 68:91-107 (in Japanese with English abstract)

Yoshida K, Hasegawa A, Okada T, linuma T, Ito Y, Asano Y (2012) Stress before and after the 2011 great Tohoku-oki earthquake and induced earthquakes in inland areas of eastern Japan. Geophys Res Lett 39:L03302. https://doi.org/10.1029/2011GL049729

Yoshida K, Hasegawa A, Okada T (2015) Spatial variation of stress orientations in NE Japan revealed by dense seismic observations. Tectonophysics 647-648:63-72. https://doi.org/10.1016/j.tecto.2015.02.013

Yoshida K, Hasegawa A, Yoshida T, Matsuzawa T (2019) Heterogeneities in stress and strength in Tohoku and its relationship with earthquake sequences triggered by the 2011 M9 Tohoku-Oki earthquake. Pure Appl Geophys 176(3):1335-1355. https://doi.org/10.1007/s00024-018-2073-9

Yukutake Y, Takeda T, Yoshida A (2015) The applicability of frictional reactivation theory to active faults in Japan based on slip tendency analysis. Earth Planet Sci Lett 411:188-198. https://doi.org/10.1016/j.epsl.2014.12.005

\section{Publisher's Note}

Springer Nature remains neutral with regard to jurisdictional claims in published maps and institutional affiliations. 